\title{
The differential effect of basic fibroblast growth factor and stromal cell-derived factor-1 pretreatment on bone morrow mesenchymal stem cells osteogenic differentiation potency
}

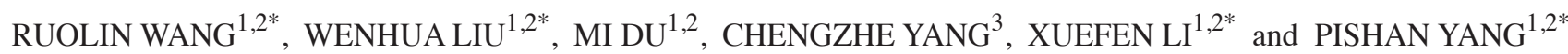 \\ ${ }^{1}$ Department of Periodontology, School of Stomatology, Shandong University; \\ ${ }^{2}$ Shandong Provincial Key Laboratory of Oral Tissue Regeneration; ${ }^{3}$ Department of Oral and Maxillofacial Surgery, \\ Qilu Hospital and Institute of Stomatology, Shandong University, Jinan, Shandong 250012, P.R. China
}

Received June 16, 2017; Accepted November 3, 2017

DOI: $10.3892 / \mathrm{mmr} .2017 .8316$

\begin{abstract}
In situ tissue engineering has become a novel strategy to repair periodontal/bone tissue defects. The choice of cytokines that promote the recruitment and proliferation, and potentiate and maintain the osteogenic differentiation ability of mesenchymal stem cells (MSCs) is the key point in this technique. Stromal cell-derived factor-1 (SDF-1) and basic fibroblast growth factor (bFGF) have the ability to promote the recruitment, and proliferation of MSCs; however, the differential effect of SDF-1 and bFGF pretreatment on MSC osteogenic differentiation potency remains to be explored. The present study comparatively observed osteogenic differentiation of bone morrow MSCs (BMMSCs) pretreated by bFGF or SDF-1 in vitro. The gene and protein expression levels of alkaline phosphatase (ALP), runt related transcription factor 2 (Runx-2) and bone sialoprotein (BSP) were detected using reverse transcription-quantitative polymerase chain reaction and western blotting. The results showed that the expression of ALP mRNA on day 3, and BSP and Runx-2 mRNA on day 7 in the bFGF pretreatment group was significantly higher than those in SDF-1 pretreatment group. Expression levels of Runx-2 mRNA, and ALP and Runx-2 protein on day 3 in the SDF-1 pretreatment group were higher than those in the bFGF pretreatment group. However, there was no significant difference in osteogenic differentiation ability on day 14 and 28
\end{abstract}

Correspondence to: Dr Xuefen Li or Professor Pishan Yang, Department of Periodontology, School of Stomatology, Shandong University, 44 West Wenhua Road, Jinan, Shandong 250012, P.R. China

E-mail: m1308935782@163.com

E-mail: yangps@sdu.edu.cn

${ }^{*}$ Contributed equally

Key words: basic fibroblast growth factor, stromal cell-derived factor-1, in situ tissue engineering, osteogenic differentiation, stem cell homing between the bFGF- or SDF-1-pretreatment groups and the control. In conclusion, bFGF and SDF-1 pretreatment inhibits osteogenic differentiation of BMMSCs at the early stage, promotes it in the medium phase, and maintains it in the later stage during osteogenic induction, particularly at the mRNA level. Out of the two cytokines, bFGF appeared to have a greater effect on osteogenic differentiation.

\section{Introduction}

Periodontitis is a kind of chronic inflammatory diseases caused by bacteria, which can impact soft and hard tissue around tooth (1). The ideal results of periodontal treatment is to obtain tissue regeneration (2). Periodontal regeneration is a complex process that requires the coordination of proliferation and differentiation of functional cells. Firstly, residual periodontal stem cells (PDLSCs), alveolar perivascular or systemic mesenchymal stem cells (MSCs) begin to proliferate and migrate to the defect. Then these cells differentiate multidirectionally, forming new cementoblast, periodontal fibroblasts and osteoblasts (3). Apparently, the number and quality of regenerative cells in defect area is the key to periodontal regeneration. However, due to the chronic inflammation, the number of regenerative cells in the periodontal defect area is inadequate and the function is compromised. Tissue engineering technique centered on stem cell therapy is one of the main strategies for the current study of periodontal regeneration. In brief, tissue engineering is an emerging discipline that combines seed cells, scaffold materials and cytokines. After a period of time of cultivation in vitro, the compounds were implanted in vivo to form new tissues and organs (4). The development of tissue engineering leads to new prospects for tissue or organ repair, but there are still some disadvantages: exogenous stem cells may cause immune rejection; autologous stem cells probably cause a secondary injury to the patient; although PDLSCs and dental pulp stem cells can be derived from extracted teeth under special circumstances, the process of collection, cultivation and re-transplantation for seed cells takes long time and high cost (5). Therefore, the clinical transformation of tissue engineering techniques in periodontal regeneration 
faces challenges. In order to overcome the shortcomings of traditional tissue engineering techniques, the researchers tried to strengthen the endogenous wound healing process by stimulating body's own repair ability. This strategy of tissue regeneration without the need for exogenous cell transplants is named in situ tissue engineering technique (6). It has been proved in medical disciplines that, through the endogenous stem cell migration to the damaged area, tissue regeneration can be achieved without exogenous cell transplantation (7-9). Recruitment of enough endogenous functional cells to the defect regions and promotion of their committed differentiation at appropriate times to re-establish the destroyed periodontium becomes a new strategy for periodontal regeneration (10).

The key elements of in situ tissue engineering are the application of chemokine and biomaterials with chemotaxis. The recruitment for MSCs can be accomplished through different bioactive factors such as stromal cell-derived factor-1 (SDF-1), bone morphogenetic protein (BMP), fibroblast growth factor (FGF) and platelet derived growth factor (PDGF) (11). However, the optimal choice of factors has not been determined. SDF-1, now named as CXCL12, is a kind of classical chemotactic agent, which is constitutively expressed by human gingival fibroblasts (HGFs) and by human periodontal ligament (PDL) fibroblasts (HPDLFs) (12). SDF-1 and its receptor, $\mathrm{C}-\mathrm{X}-\mathrm{C}$ motif receptor 4 (CXCR4) play a vital role in the development of embryonic organs (13), maintaining tissue homeostasis after birth (14) and bone remodeling (15). CXCR4 expression is found on the cell surface in human and rat MSCs (16) and human PDLSCs (12). A series of studies have shown that the local expression of SDF-1 increases after injury of tissues like heart, brain, liver and bone, and MSCs can be recruited and repair damaged tissues (17-20). Moreover, SDF-1 can promote the migration and proliferation of stem cells and then enhance periodontal bone regeneration $(10,21)$. Besides, SDF-1 has the ability to promote angiogenesis (22) and reduces inflammation, which could prevent the host from strong immune response to the implant (23). bFGF also has extensive biological activities, which is present in basement membranes, in the subendothelial extracellular matrix of blood vessels in normal tissue and in periodontal ligament (24). The study showed that bFGF can regulate cell proliferation and differentiation $(25,26)$ and is able to promote angiogenesis (27) and nerve regeneration $(28,29)$. In an in vitro experiment, bFGF was found to sustain self-renewal ability, while maintaining differentiation potency $(30,31)$. Furthermore, documents and our previous studies show that bFGF significantly promote migration of MSCs $(25,32)$ and chemotactic activity of bFGF for MSCs is even stronger than SDF-1 (33) or BMP-2 (32).

In periodontal tissue regeneration, the proliferation and differentiation of functional cells is a continuous process. The first step is the migration and proliferation of PDLSCs and MSCs, which make the periodontal defect to be occupied by sufficient precursors. These precursors then multi-directionally differentiate, forming the periodontal ligament, alveolar bone and cementum. This implies that apart from direct effect on migration and proliferation, the osteoblastic and cementoblastic differentiation potency of MSCs treated by cytokines will determine the final outcome of periodontal regeneration. To our limited knowledge, comparing investigation of different cytokines on this aspect has not been conducted, thus, osteogenic differentiation capability of BMMSCs (ST2 cell line) pretreated separately with bFGF and SDF-1 was compared here. It will provide certain guidance for the selection of chemotactic agent in the in situ periodontal tissue engineering.

\section{Materials and methods}

BMMSC culture. BMMSCs (ST2 cell line, donated by key laboratory of oral tissue regeneration in Shandong province) were recovered from cryopreservation. Then the cells were cultured in maintenance medium (DMEM containing 10\% fetal bovine serum, $100 \mathrm{U} / \mathrm{ml}$ penicillin $\mathrm{G}$ and $100 \mu \mathrm{g} / \mathrm{ml}$ streptomycin, Hyclone, USA). BMMSCs were cultured in an incubator at $37^{\circ} \mathrm{C}$ with an atmosphere comprising $95 \%$ air and $5 \% \mathrm{CO}_{2}$ and $100 \%$ relative humidity. The medium was changed every other day.

BMMSC pretreatment by bFGF and SDF-1. BMMSCs were cultured till the 3rd generation, non-adherent cells were discarded and adherent cells were washed three times using phosphate buffered saline (PBS). All cells were divided into three groups: the control group (cultured in maintenance medium, $1 \%$ fetal bovine serum, $100 \mathrm{U} / \mathrm{ml}$ penicillin $\mathrm{G}$ and $100 \mu \mathrm{g} / \mathrm{ml}$ streptomycin), bFGF-pretreated group (cultured in maintenance medium with $20 \mathrm{ng} / \mathrm{ml} \mathrm{bFGF,} 1 \%$ fetal bovine serum, $100 \mathrm{U} / \mathrm{ml}$ penicillin $\mathrm{G}$ and $100 \mu \mathrm{g} / \mathrm{ml}$ streptomycin), SDF-1-pretreted group (cultured in maintenance medium with $200 \mathrm{ng} / \mathrm{ml} \mathrm{SDF}-1,1 \%$ fetal bovine serum, $100 \mathrm{U} / \mathrm{ml}$ penicillin $\mathrm{G}$ and $100 \mu \mathrm{g} / \mathrm{ml}$ streptomycin). Cells were incubated according to above grouping for $48 \mathrm{~h}$.

BMMSC osteogenic differentiation assay. After $48 \mathrm{~h}$ of culture, three groups of cells were washed three times with PBS and cultured in an osteogenic medium $\left(10^{-8} \mathrm{M}\right.$ dexamethasone (Sigma-Aldrich; Merck KGaA, Darmstadt, Germany), $10 \mathrm{mM} \beta$-glycerophosphate (Sigma-Aldrich; Merck KGaA) and $50 \mathrm{ng} / \mathrm{ml}$ ascorbic acid (Sigma-Aldrich; Merck KGaA) in DMEM-F12 containing 10\% FBS) for 3, 7, 14 and 28 days for following experiments.

RT-PCR assay. After 3, 7, 14 days of osteogenic induction, cell samples were collected. Total RNA was quantified with GeneQuant pro spectrophotometer (Biochrom, Ltd., Cambridge, UK) and was reversely transcribed into cDNA with TRIzol kit (Triton X-100; Ameresco, Inc., Framingham, MA, USA). Reverse transcription was conducted in a $20 \mu \mathrm{l}$ reaction volume with the following protocol: $37^{\circ} \mathrm{C}$ for $15 \mathrm{~min}$ and $85^{\circ} \mathrm{C}$ for $5 \mathrm{sec}$. RT-PCR was conducted by real-time fluorescent quantitative PCR (Light Cycler II 480; Roche, Mannheim, Germany). cDNA were kept at $-20^{\circ} \mathrm{C}$ for the following measure. Expression levels of osteoblastic genes including alkaline phosphatase (ALP), runt related transcription factor 2 (Runx-2) and bone sialoprotein (BSP). The primer sequences for ALP, BSP, Runx-2 were designed as Table I and GAPDH used as a reference gene. Each reaction mixture had a total volume of $10 \mu 1$ and contained SYBR $\left(\mathrm{SYBR}^{\circledR}\right.$ Premix Ex Taq ${ }^{\text {TM }}$ II kit; Takara Biotechnology Co., Ltd., Dalian, 
Table I. Primer sequences for RT-PCR.

\begin{tabular}{lll}
\hline Gene & \multicolumn{1}{c}{ Forward primer } & \multicolumn{1}{c}{ Reverse primer } \\
\hline GAPDH & 5'-AGGTCGGTGTGAACGGATTTG-3' & 5'-TGTAGACCATGTAGTTGAGGTCA-3' \\
ALP & 5'-CTTGCTGGTGGAAGGAGGCAGG-3' & 5'-GGAGCACAGGAAGTTGGGAC-3' \\
BSP & 5'-CAGGGAGGCAGTGACTCTTC-3' & 5'-AGTGTGGAAAGTGTGGCGTT-3' \\
Runx-2 & 5'-CCCAGCCACCTTTACCTACA-3' & 5'-TATGGAGTGCTGCTGGTCTG-3'
\end{tabular}

GAPDH, glyceraldehyde-3-phosphate dehydrogenase; ALP, alkaline phosphatase; Runx-2, runt related transcription factor 2; BSP, bone sialoprotein.

China) $3.6 \mu 1$, sterile threefold-distilled water $5 \mu 1$, cDNA $1 \mu \mathrm{l}$, forward primer and reverse peimer $0.2 \mu \mathrm{l}$ respectively. RT-PCR was conducted with the following protocols: 1 cycle of $95^{\circ} \mathrm{C}$ for $30 \mathrm{sec}$, followed by 45 cycles of $95^{\circ} \mathrm{C}$ for $5 \mathrm{sec}$ and $60^{\circ} \mathrm{C}$ for $35 \mathrm{sec}$, and then 1 cycles of $95^{\circ} \mathrm{C}$ for $15 \mathrm{sec}$ and $60^{\circ} \mathrm{C}$ for $60 \mathrm{sec}$, at last $1 \mathrm{cycle}$ of $40^{\circ} \mathrm{C}$ for $30 \mathrm{sec}$.

Western blot assay. ALP, BSP and Runx-2 were also measured by western blot analysis at 3,7 and14 days of osteogenic induction. Proteins were extracted from the cells by ice-cold RIPA lysis buffer (Beijing Solarbio Science \& Technology Co., Ltd., Beijing, China) containing 1\% phenylmethylsulfonyl fluoride (PMSF; Beijing Solarbio Science \& Technology Co., Ltd.) for $30 \mathrm{~min}$. Lysate were collected and centrifugated at $12,000 \mathrm{x} \mathrm{g}$ at $4{ }^{\circ} \mathrm{C}$ for $15 \mathrm{~min}$ and preserved at $-80{ }^{\circ} \mathrm{C}$ for later examination. Bovine serum albumin (BSA) was used for establishing standard curve of protein concentration according to the manufacturer's instructions of BSA (Beijing Solarbio Science \& Technology Co., Ltd.).

Samples and BSA maker were subjected to $10 \%$ SDS-PAGE and transferred to polyvinylidene difluoride membranes (PVDF; GE Amersham, Fairfield, CT, USA) by electroblotting. Filters were then blocked in 5\% non-fat milk-Tris buffered saline (TBS)- $0.05 \%$ Tween-20 for $1 \mathrm{~h}$ and incubated with the primary antibodies overnight at $4^{\circ} \mathrm{C}$ as followed: rabbit monoclonal anti-Runx-2 antibody (1:2,000 dilution, ab23981; Abcam, Cambridge, UK), rabbit monoclonal anti-ALP antibody (1:500 dilution, ab108337; Abcam), and rabbit monoclonal anti-BSP antibody (1:1,000 dilution; Santa Cruz Biotechnology, Inc., Dallas, TX, USA). PVDF membranes were washed by TBST three times for $10 \mathrm{~min}$. Then, Filters were blocked in 5\% non-fat milk-Tris buffered saline (TBS)-0.05\% Tween-20 with the secondary antibodies (1:20,000 dilution) for $1 \mathrm{~h}$. The bands corresponding to Runx-2, ALP and BSP were detected using a chemiluminescence reagent (Merck Millipore, Darmstadt, Germany). Images were collected with image $\mathbf{J}$ (National Institutes of Health, Bethesda, MD, USA).

Mineral nodules formation assay. After 28 days of culture, mineralized nodules were stained. Cells were washed three times with PBS and incubated with $0.5 \mathrm{ml}$ of alizarin red $\mathrm{S}$ solution (1\%) for 30 min until the mineralized nodules had stained red. Excessive reagents were washed by distilled water and dried. Digital images were captured using a light microscope (IX71; Olympus Corporation, Tokyo, Japan). Numbers
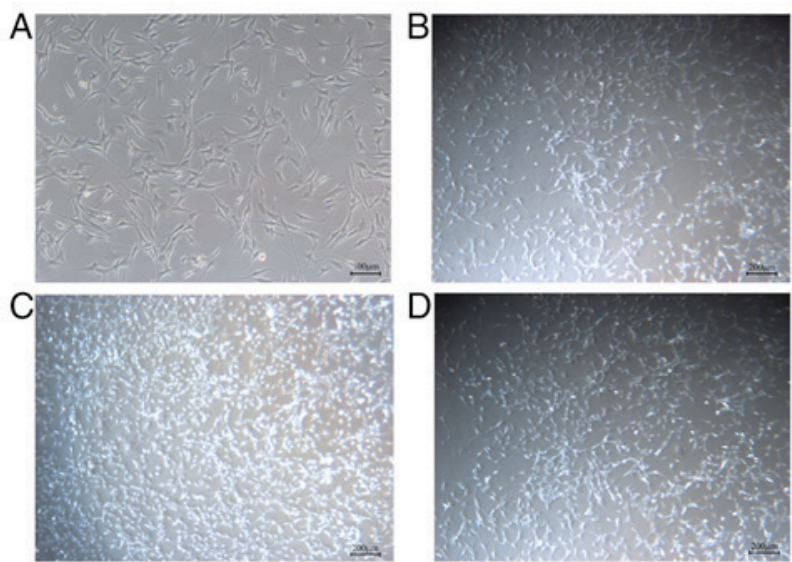

Figure 1. Morphology observation for BMMSCs. (A) ST2 cells primarily cultured for $24 \mathrm{~h}$ (original magnificence, x100); (B) Negative group after $48 \mathrm{~h}$ of re-culture (original magnification, $\mathrm{x} 40$ ); (C) bFGF-pretreated group after $48 \mathrm{~h}$ of re-culture (original magnification, $\mathrm{x} 40$ ); (D) SDF-1-pretreated group after $48 \mathrm{~h}$ of re-culture (original magnification, $\mathrm{x} 40$ ). BMMSCs, bone morrow mesenchymal stem cells; bFGF, basic fibroblast growth factor; SDF-1, stromal cell-derived factor-1.

of calcium nodules were observed in the field of vision under original magnification $\mathrm{x} 100$.

Statistical analysis. The experimental measurement data were given as the mean \pm standard deviation for each experiment and analyzed using SPSS (version 17.0; SPSS, Inc., Chicago, IL, USA). A one-way analysis of variance (ANOVA) was used for comparison between the three groups, and LSD used for pairwise comparison. For each test, $\mathrm{P}<0.05$ was considered to indicate a statistically significant difference.

\section{Results}

Morphology observation for BMMSCs. Adherent growth of ST2 cells was visible after recovery or passage. Cells were polygonal or long fibrous, with elongated and intersected connections between cells (Fig. 1A). All cells were in good condition and proliferate fast, with a $90 \%$ confluency at the 2 to 3 days after inoculation. After pretreated by bFGF and SDF-1 for $24 \mathrm{~h}$, no significant change in cell morphology can be observed. However, the number of BMMSCs treated by bFGF and SDF-1 increased and bFGF-pretreated group increased more apparently than SDF-1 (Fig. 1B-D). 

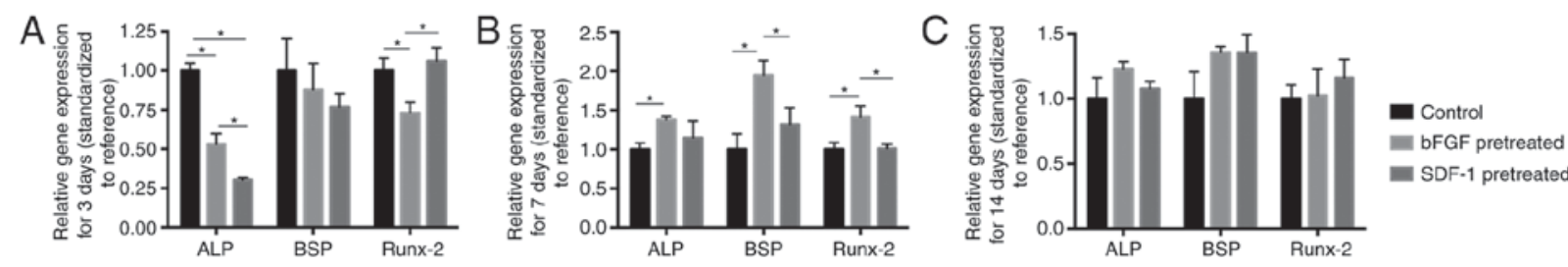

Figure 2. RT-qPCR analysis of ALP, BSP and Runx-2 mRNA expression levels in bFGF-, SDF-1-pretreated and control groups. (A) At day 3, ALP expression in bFGF- and SDF-1-pretreatment groups is significantly lower than that in control group, and Runx-2 expression in bFGF-pretreated group is significantly lower than control and SDF-1-pretreated group. (B) At day 7, significantly higher levels of ALP were discernible in bFGF-pretreated groups compared with control group, while bFGF pretreatment significantly promoted BSP and Runx-2 expression compared with control group and SDF-1-pretreated group. (C) At day 14, no significant difference was shown among groups. " $\mathrm{P}<0.05$. ALP, alkaline phosphatase; BSP, bone sialoprotein; Runx-2, runt related transcription factor 2 ; bFGF, basic fibroblast growth factor; SDF-1, stromal cell-derived factor-1.
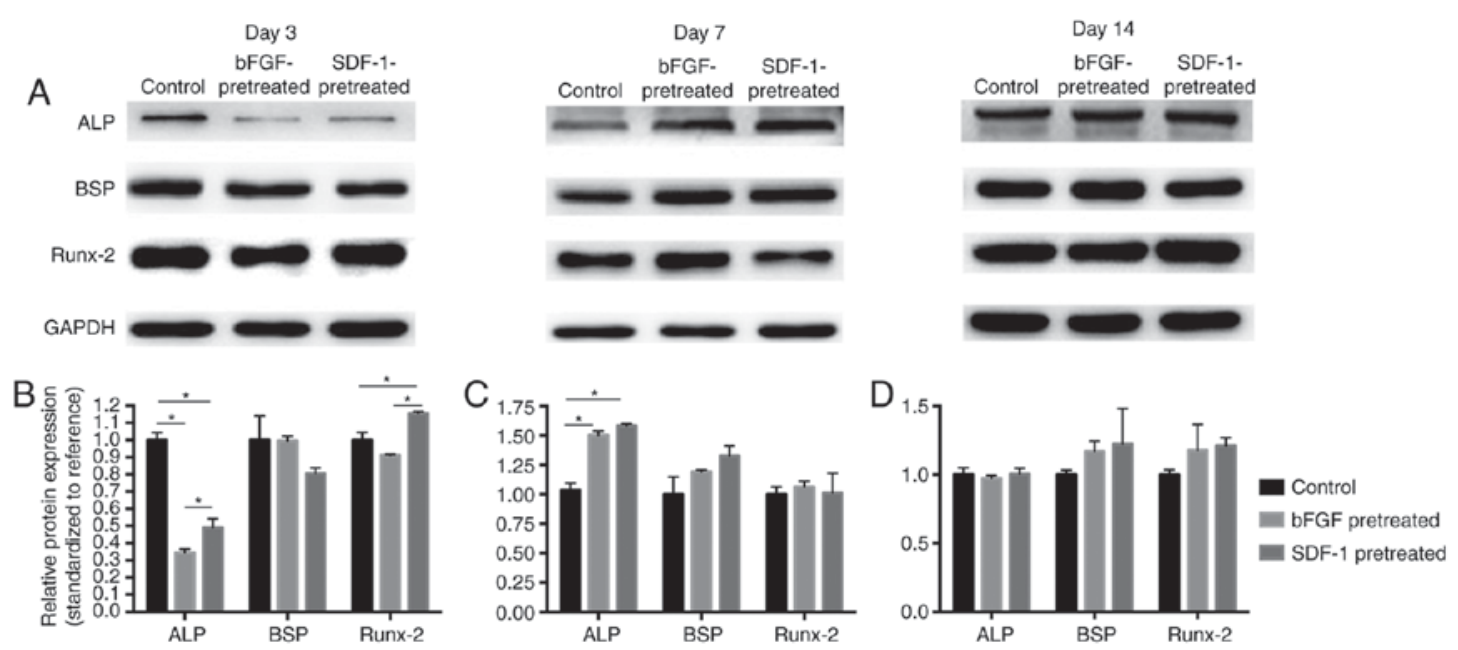

Figure 3. Western-blot analysis of ALP, BSP and Runx-2 protean expression levels in bFGF-, SDF-1-pretreated and control groups. (A) Representative blots. (B) At day 3, ALP expression in bFGF- and SDF-1-pretreatment groups is significantly lower than that in control group ( $<<0.05)$, while SDF-1 pretreatment significantly promoted Runx-2 expression. (C) At day 7, significantly higher levels of ALP were discernible in bFGF- and SDF-1-pretreated groups compared with control group. (D) At day 14, no significant difference was shown among groups, "P<0.05. ALP, alkaline phosphatase; BSP, bone sialoprotein; Runx-2, runt related transcription factor 2; bFGF, basic fibroblast growth factor; SDF-1, stromal cell-derived factor-1.

RT-qPCR analysis. RT-qPCT showed that at day 3, BMMSCs pretreated by bFGF showed significantly lower ALP and Runx-2 mRNA expression and BMMSCs pretreated by SDF-1 showed significantly lower ALP mRNA expression compared with negative group (Fig. 2A). However, at day 7, bFGF pretreatment significantly promoted Runx-2, BSP and ALP mRNA expressions compared with negative group. Moreover, bFGF-pretreated group exhibited significantly higher expression of BSP and Runx-2 mRNA at day 7 than SDF-1-pretreated group (Fig. 2B). At day 14, both bFGFand SDF-1-pretreated group had no significantly different effect on osteogenic differentiation compared with negative group (Fig. 2C).

Western blot analysis. Western Blot technique was used to detect the level of protein expression in the control group, bFGF pretreatment group and the SDF-1 pretreatment group (Fig. 3). The result showed that, at day 3, ALP expression in bFGF- and SDF-1-pretreated groups is significantly lower than that in control group $(\mathrm{P}<0.05)$, while SDF-1 pretreatment significantly promoted Runx-2 expression (Fig. 3B). At day 7 , bFGF- and SDF-1-pretreatment groups significantly increased ALP expression compared with control group $(\mathrm{P}<0.05)$ (Fig. 3C). No significant difference was found among groups at day 14 (Fig. 3D). However, at day 3, the ALP and Runx-2 protein expression in SDF-1-pretreated group significantly higher than that in bFGF-pretreated group (Fig. 3B).

Mineral nodules formation. After 28 days of mineralized induced culture, mineral nodules were stained and evaluated by macroscopic and the microscopic observation. The bFGFand SDF-1-pretreated groups were able to form similar number of calcified nodules to the control group (Fig. 4).

\section{Discussion}

This study set three groups: negative control, bFGF-pretreated group and SDF-1-pretreated group. First, the effect of bFGF and SDF-1 on morphology and numbers of BMMSCs were observed. Results showed that morphology of BMMSCs did not change apparently after treated by bFGF and SDF-1 for $24 \mathrm{~h}$, while number of BMMSCs obviously increased. The number of cells treated by bFGF increased more apparently in relation to SDF-1. This suggests that both bFGF and SDF-1 promote BMMSC proliferation and bFGF has stronger effect than SDF-1. Then, osteogenic differentiation markers in bFGF- and SDF-1-pretreated BMMSCs were detected after osteogenic induction culture. Results revealed a differential 

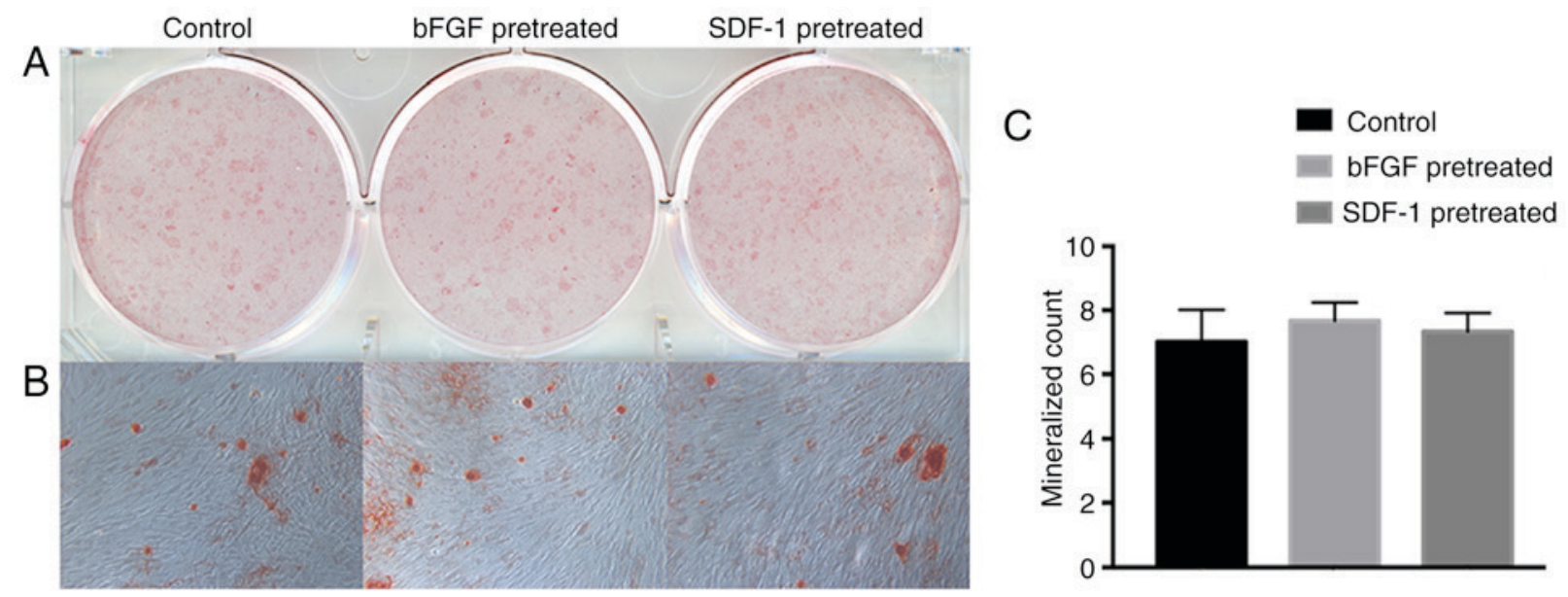

Figure 4. Effect of bFGF and SDF-1 pretreatment on the formation of calcium nodules. (A) Macroscopic image for three groups. (B) Microscopic image for three groups (original magnification, x400). (C) Mineral nodules counting for three groups. bFGF, basic fibroblast growth factor; SDF-1, stromal cell-derived factor-1.

effect of bFGF- and SDF-1-pretreatment on osteogenic differentiation potency of BMMSCs.

BMMSCs pretreated in maintenance medium containing $20 \mathrm{ng} / \mathrm{ml} \mathrm{bFGF}$ or $200 \mathrm{ng} / \mathrm{ml} \mathrm{SDF}-1$ for $48 \mathrm{~h}$ were re-cultured in an osteogenic medium. The ALP and Runx-2 mRNA expression and ALP protein expression in bFGF pretreatment group were significantly lower than in the control group after 3 days of cultivation. However, at day 7, expressions of ALP, BSP and Runx-2 mRNA and ALP protein were significantly higher than control. No significant difference in osteogenic markers was proved on day 14 and 28. This result suggests that direct stimulation by bFGF temporally inhibit osteogenic differentiation of BMMSCs but bFGF pretreatment enhance, at least maintain, medium and later osteogenic differentiation potency. Direct inhibition of osteogenic differentiation of BMMSC by bFGF was consistent with the experiment conducted by Tasso (34), who proved that bFGF could select MSCs with higher proliferation activity. Cells pretreated by bFGF had higher proliferation activity, lower degree of differentiation, and significantly lower ALP level than the control group. The results of enhancing later osteogenic differentiation potency by bFGF were similar to the basic pattern proved by our previous experiment: on the day 7 after pretreated by bFGF, rat BMMSCs showed the strongest osteogenic differentiation capability. On contrast, our previous study also showed enhanced osteogenic differentiation capability after 3 and 14 days pretreated by bFGF (32). It is difficult to explain the exact reason of the difference, while difference of cells used in two studies may be main causes. Nevertheless, it is a fact that bFGF can strengthen the osteogenic potential of MSCs.

SDF-1-pretreated group showed similar result to bFGF-pretreated group, that is, osteogenesis was first inhibited and then promoted. But there were also some differences between two groups. Expressions of ALP mRNA on day 3 and BSP and Runx-2 mRNA on day 7 in bFGF pretreatment group were significantly higher than those in SDF-1 pretreatment group; expressions of Runx-2 mRNA and ALP, Runx-2 protein on day 3 in SDF-1 pretreatment group were higher than those in bFGF pretreatment group. The results suggest that SDF-1-pretreated group put up lower inhibition in the early period, but also weaker promotion in the later stage for osteogenic differentiation compared with bFGF.

The transcription and translation process itself is influenced by many factors. Protein regulation is multi-level, multi-temporal and multi-type and RNA alone does not determine the proteins. Other factors such as protein half-life and synthesis speed also affect the levels of protein expression. Many studies have found this phenomenon $(35,36)$. This may be the reason why inconsistent expressions of mRNA and protean of some markers in BMMSCs pretreated by bFGF or SDF-1 (Figs. 2B and 3B).

SDF-1 has received a lot of attention in relation to its biological activities such as cell recruitment, migration, and proliferation, and also the effect to increases the periodontal regeneration. Our previous study showed that SDF-1 can promote stem cell recruitment, migration and proliferation, and promotes periodontal regeneration (10). At cell level, studies have shown that many stem cells have the expression of CXCR4 (SDF-1 receptor), indicating that SDF-1/CRCX4 signal axis plays an important role in the migration and homing of stem cell (20). In addition, SDF-1 can significantly promote proliferation of osteoblasts; in the region of the bone reconstruction, osteoblast can express CXCL12/CXCR4, and also induce the expression of collagen type I (37). Some studies suggest that SDF-1 regulate BMP2-induced differentiation of primary MSCs into osteoblastic cells. Blocking SDF-1/CXCR4 signal axis can inhibit differentiation of MSCs which mediated by BMP-2 (38), suggesting that SDF-1 play a role in osteogenic differentiation and promotion of bone regeneration.

Meanwhile, the extensive studies have shown that bFGF can regulate cell proliferation, migration and differentiation, and is able to promote angiogenesis (27) and nerve regeneration $(28,29)$. There have been numerous studies showing that bFGF can sustain self-renewal and multidirectional potential of embryonic stem cells and various forms of adult stem cell. Studies based on rabbit embryonic stem cells (rESCs) show that signaling pathways involved in stemness maintenance of rESCs includes TGF- $\beta$, FGF and Wnt. Blocking the FGF 
downstream MAPK/ERK signal and PI3K/AKT pathway leads to differentiation of rESCs (39). In addition, bFGF plays an important role in maintaining stemness of stem cells isolated from human exfoliated deciduous teeth and apical papilla to enhance colony forming unit capacity and promote gene expression level of pluripotent markers such as OCT4, REX1 and NANOG $(40,41)$.

In the process of bone regeneration promoted by MSCs, firstly, a sufficient cell number is necessary; secondly, primary cells differentiate to functional cells like osteoblast, cementoblast, osteoclast and so on. Thus, both homing and proliferation and following osteogenic differentiation are important events for bone tissue regeneration. Comparative studies have shown that bFGF has greater chemotaxis ability to MSCs than SDF-1 $(31,42)$. The present study suggests that bFGF has an advantage over SDF-1 in promoting proliferation and maintaining the osteogenic potential for BMMSCs.

Angiogenesis and nerve regeneration play an important role in periodontal/bone regeneration. Previous study has also shown that angiogenic factors are expressed during the early phases of bone formation and remodeling for reestablishment of the vasculature, while osteogenic growth factors can continuously expressed in the later phases $(43,44)$, which is in favor of bone regeneration. It has been demonstrated that a dose of SDF-1 released from gelatin hydrogels enhanced angiogenesis because of the recruitment of cells which are effective in angiogenesis (45). The bFGF has already been extensively studied that it can regulate cell proliferation, cell migration and cell differentiation, able to promote angiogenesis and nerve regeneration. Angiogenesis is an important process of early bone formation and remodeling. At the same time, nerve regeneration can improve the quality of newbone. Potential to improve fracture healing in animal models of bFGF has been studied already (46).

All in all, from the aspect of migration and proliferation, or maintaining stemness and differentiation potential, bFGF possesses some advantage over SDF-1 in the in situ periodontal tissue engineering. The differential effect on angiogenesis and nerve regeneration, activated different signal pathways in MSCs and the periodontal regeneration effects in vivo by bFGF and SDF-1still need to be further evaluated.

\section{Acknowledgements}

This study was supported by the National Natural Science Foundation of China (81271141 to P. Y.) and the Construction Engineering Special Fund of 'Taishan Scholars'.

\section{References}

1. Flemming TF: Periodontitis. Ann Periodontol 4: 32-38, 1999

2. Villar CC and Cochran DL: Regeneration of periodontal tissues: Guided tissue regeneration. Dent Clin North Am 54: 73-92, 2010.

3. Melcher AH: On the repair potential of periodontal tissues. J Periodontol 47: 256-260, 1976.

4. Langer R and Vacanti JP: Tissue engineering. Science 260: 920-926, 1993.

5. Sengupta D, Waldman SD and Li S: From in vitro to in situ tissue engineering. Ann Biomed Eng 42: 1537-1545, 2014.

6. Nakahara T, Nakamura T, Kobayashi E, Inoue M, Shigeno K, Tabata Y, Eto K and Shimizu Y: Novel approach to regeneration of periodontal tissues based on in situ tissue engineering: Effects of controlled release of basic fibroblast growth factor from a sandwich membrane. Tissue Eng 9: 153-162, 2003.
7. Shao Z, Zhang X, Pi Y, Wang X, Jia Z, Zhu J, Wang X, Jia Z, Zhu J, Dai L, et al: Polycaprolactone electrospun mesh conjugated with an MSC affinity peptide for MSC homing in vivo. Biomaterials 33: 3375-3387, 2012.

8. Shafiq M, Lee SH, Jung Y and Kim SH: Strategies for recruitment of stem cells to treat myocardial infarction. Curr Pharm Des 21: 1584-1597, 2015.

9. Lee CH, Cook JL, Mendelson A, Moioli EK, Yao H and Mao JJ: Regeneration of the articular surface of the rabbit synovial joint by cell homing: A proof of concept study. Lancet 376: 440-448, 2010.

10. Liu H, Li M, Du L, Yang P and Ge S: Local administration of stromal cell-derived factor-1 promotes stem cell recruitment and bone regeneration in a rat periodontal bone defect model. Mater Sci Eng C Mater Biol Appl 53: 83-94, 2015.

11. Vanden Berg-Foels WS: In situ tissue regeneration: Chemoattractants for endogenous stem cell recruitment. Tissue Eng Part B Rev 20: 28-39, 2014.

12. Du L, Yang P and Ge S: Stromal cell-derived factor-1 significantly induces proliferation, migration, and collagen type I expression in a human periodontal ligament stem cell subpopulation. J Periodontol 83: 379-388, 2012.

13. Rehimi R, Khalida N, Yusuf F, Dai F, Morosan-Puopolo G and Brand-Saberi B: Stromal-derived factor-1 (SDF-1) expression during early chick development. Int J Dev Biol 52: 87-92, 2008.

14. Baggiolini M: Chemokines and leukocyte traffic. Nature 392: 565-568, 1998.

15. Yu X, Huang Y, Collin-Osdoby P and Osdoby P: Stromal cell-derived factor-1 (SDF-1) recruits osteoclast precursors by inducing chemotaxis, matrix metalloproteinase-9 (MMP-9) activity, and collagen transmigration. J Bone Miner Res 18: 1404-1418, 2003.

16. Wynn RF, Hart CA, Corradi-Perini C, O'Neill L, Evans CA, Wraith JE, Fairbairn LJ and Bellantuono I: A small proportion of mesenchymal stem cells strongly expresses functionally active CXCR4 receptor capable of promoting migration to bone marrow. Blood 104: 2643-2645, 2004.

17. Kucia M, Ratajczak J, Reca R, Janowska-Wieczorek A and Ratajczak MZ: Tissue-specific muscle, neural and liver stem/ progenitor cells reside in the bone marrow, respond to an SDF-1 gradient and are mobilized into peripheral blood during stress and tissue injury. Blood Cells Mol Dis 32: 52-57, 2004.

18. Abbott JD, Huang Y, Liu D, Hickey R, Krause DS and Giordano FJ: Stromal cell-derived factor-1alpha plays a critical role in stem cell recruitment to the heart after myocardial infarction but is not sufficient to induce homing in the absence of injury. Circulation 110: 3300-3305, 2004.

19. Ji JF, He BP, Dheen ST and Tay SS: Interactions of chemokines and chemokine receptors mediate the migration of mesenchymal stem cells to the impaired site in the brain after hypoglossal nerve injury. Stem Cells 22: 415-427, 2004.

20. Ji W, Yang F, Ma J, Bouma MJ, Boerman OC, Chen Z, van den Beucken JJ and Jansen JA: Incorporation of stromal cell-derived factor-1alpha in PCL/gelatin electrospun membranes for guided bone regeneration. Biomaterials 34: 735-745, 2013.

21. Xu J, Chen Y, Liu Y, Zhang J, Kang Q, Ho K, Chai Y and Li G: Effect of SDF-1/Cxcr4 signaling antagonist AMD3100 on bone mineralization in distraction osteogenesis. Calcif Tissue Int 100: 641-652, 2017.

22. Ratanavaraporn J, Furuya H, Kohara H and Tabata Y: Synergistic effects of the dual release of stromal cell-derived factor-1 and bone morphogenetic protein-2 from hydrogels on bone regeneration. Biomaterials 32: 2797-2811, 2011.

23. Thevenot PT, Nair AM, Shen J, Lotfi P, Ko CY and Tang L: The effect of incorporation of SDF-1alpha into PLGA scaffolds on stem cell recruitment and the inflammatory response. Biomaterials 31: 3997-4008, 2010.

24. Grzibovskis M, Urtane I and Pilmane M: Specific signaling molecule expression in periodontal ligaments in different age groups: Pilot study. Stomatologija 13: 117-122, 2011.

25. Osathanon T, Nowwarote $\mathrm{N}$ and Pavasant P: Basic fibroblast growth factor inhibits mineralization but induces neuronal differentiation by human dental pulp stem cells through a FGFR and PLCgamma signaling pathway. J Cell Biochem 112: 1807-1816, 2011.

26. Narong $\mathrm{S}$ and Leelawat $\mathrm{K}$ : Basic fibroblast growth factor induces cholangio-carcinoma cell migration via activation of the MEK1/2 pathway. Oncol Lett 2: 821-825, 2011. 
27. Horikoshi-Ishihara H, Tobita M, Tajima S, Tanaka R, Oshita T, Tabata Y and Mizuno H: Coadministration of adipose-derived stem cells and control-released basic fibroblast growth factor facilitates angiogenesis in a murine ischemic hind limb model. J Vasc Surg 64: 1825-1834.e1, 2016.

28. Zhu H, Yang A, Du J, Li D, Liu M, Ding F, Gu X and Liu Y: Basic fibroblast growth factor is a key factor that induces bone marrow mesenchymal stem cells towards cells with Schwann cell phenotype. Neurosci Lett 559: 82-87, 2014.

29. Ikeda M, Uemura T, Takamatsu K, Okada M, Kazuki K, Tabata Y, Ikada Y and Nakamura H: Acceleration of peripheral nerve regeneration using nerve conduits in combination with induced pluripotent stem cell technology and a basic fibroblast growth factor drug delivery system. J Biomed Mater Res A 102: 1370-1378, 2014.

30. Li Y, Tsai YT, Hsu CW, Erol D, Yang J, Wu WH, Davis RJ, Egli D and Tsang SH: Long-term safety and efficacy of human-induced pluripotent stem cell (iPS) grafts in a preclinical model of retinitis pigmentosa. Mol Med 18: 1312-1319, 2012.

31. Levenstein ME, Ludwig TE, Xu RH, Llanas RA, VanDenHeuvel-Kramer K, Manning D and Thomson JA: Basic fibroblast growth factor support of human embryonic stem cell self-renewal. Stem Cells 24: 568-574, 2006.

32. Du M, Zhu T, Duan X, Ge S, Li N, Sun Q and Yang P: Acellular dermal matrix loading with bFGF achieves similar acceleration of bone regeneration to BMP-2 via differential effects on recruitment, proliferation and sustained osteodifferentiation of mesenchymal stem cells. Mater Sci Eng C Mater Biol Appl 70: 62-70, 2017.

33. Schmidt A, Ladage D, Schinköthe T, Klausmann U, Ulrichs C, Klinz FJ, Brixius K, Arnhold S, Desai B, Mehlhorn U, et al: Basic fibroblast growth factor controls migration in human mesenchymal stem cells. Stem Cells 24: 1750-1758, 2006.

34. Tasso R, Gaetani M, Molino E, Cattaneo A, Monticone M, Bachi A and Cancedda R: The role of bFGF on the ability of MSC to activate endogenous regenerative mechanisms in an ectopic bone formation model. Biomaterials 33: 2086-2096, 2012.

35. de Sousa Abreu R, Penalva LO, Marcotte EM and Vogel C: Global signatures of protein and mRNA expression levels. Mol Biosyst 5: 1512-1526, 2009

36. de Klerk E and 't Hoen PA: Alternative mRNA transcription, processing, and translation: Insights from RNA sequencing. Trends Genet 31: 128-139, 2015.

37. Kitamura M, Nakashima K, Kowashi Y, Fujii T, Shimauchi H, Sasano T, Furuuchi T, Fukuda M, Noguchi T, Shibutani T, et al: Periodontal tissue regeneration using fibroblast growth factor-2: Randomized controlled phase II clinical trial. PLoS One 3 : e2611, 2008
38. Hosogane N, Huang Z, Rawlins BA, Liu X, Boachie-Adjei O, Boskey AL and Zhu W: Stromal derived factor-1 regulates bone morphogenetic protein 2-induced osteogenic differentiation of primary mesenchymal stem cells. Int J Biochem Cell Biol 42: 1132-1141, 2010.

39. Wang S, Shen Y, Yuan X, Chen K, Guo X, Chen Y, Niu Y, Li J, $\mathrm{Xu} \mathrm{RH}$, Yan X, et al: Dissecting signaling pathways that govern self-renewal of rabbit embryonic stem cells. J Biol Chem 283: 35929-35940, 2008.

40. Sukarawan W, Nowwarote N, Kerdpon P, Pavasant P and Osathanon T: Effect of basic fibroblast growth factor on pluripotent marker expression and colony forming unit capacity of stem cells isolated from human exfoliated deciduous teeth. Odontology 102: 160-166, 2014.

41. Wu J, Huang GT, He W, Wang P, Tong Z, Jia Q, Dong L, Niu Z and Ni L: Basic fibroblast growth factor enhances stemness of human stem cells from the apical papilla. J Endod 38: 614-622, 2012.

42. Ponte AL, Marais E, Gallay N, Langonné A, Delorme B, Hérault $\mathrm{O}$, Charbord $\mathrm{P}$ and Domenech J: The in vitro migration capacity of human bone marrow mesenchymal stem cells: Comparison of chemokine and growth factor chemotactic activities. Stem Cells 25: 1737-1745, 2007.

43. Chen FM, Zhang M and Wu ZF: Toward delivery of multiple growth factors in tissue engineering. Biomaterials 31: 6279-6308, 2010.

44. Kempen DH, Lu L, Heijink A, Hefferan TE, Creemers LB, Maran A, Yaszemski MJ and Dhert WJ: Effect of local sequential VEGF and BMP-2 delivery on ectopic and orthotopic bone regeneration. Biomaterials 30: 2816-2825, 2009.

45. Kimura Y and Tabata Y: Controlled release of stromal-cell-derived factor-1 from gelatin hydrogels enhances angiogenesis. J Biomater Sci Polym Ed 21: 37-51, 2010.

46. Hankenson KD, Dishowitz M, Gray C and Schenker M: Angiogenesis in bone regeneration. Injury 42: 556-561, 2011.

c) (i) (-) $\odot$ This work is licensed under a Creative Commons Attribution-NonCommercial-NoDerivatives 4.0 International (CC BY-NC-ND 4.0) License. 